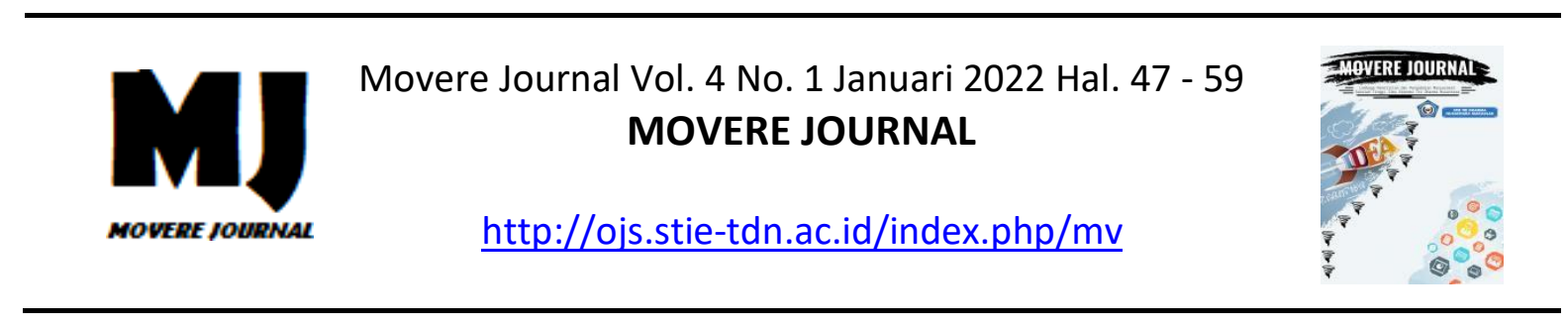

\title{
Pengaruh Lingkungan Kerja Terhadap Kepuasan Kerja Pegawai Pada Kantor Dinas Perumahan, Kawasan Permukiman Dan Pertanahan Provinsi Sulawesi Selatan
}

\author{
Ady Andardinata ${ }^{1}$, Rahmat $^{2}$ \\ Dosen STIE Tri Dharma Nusantara Makassar ${ }^{1,2}$ \\ adyandardinata173@gmail.com ${ }^{1}, \underline{\text { rahmat.k2105@gmail.com² }}{ }^{2}$
}

\begin{abstract}
Abstrak: Pengaruh Lingkungan Kerja Terhadap Kepuasan Kerja Pegawai Pada Dinas Perumahan, Permukiman dan Pertanahan Provinsi Sulawesi Selatan. Penelitian ini bertujuan untuk mengetahui pengaruh lingkungan kerja terhadap kepuasan kerja pegawai pada Dinas Perumahan, Pertanahan dan Pertanahan Provinsi Sulawesi Selatan. Jenis data yang digunakan dalam penelitian ini adalah data kualitatif dan kuantitatif. Sumber data diperoleh dari data primer dan data sekunder dengan cara menyebarkan pertanyaan atau pernyataan kepada responden. Jumlah responden yang digunakan adalah 54 orang. Metode yang digunakan dalam pengolahan data adalah analisis regresi linier sederhana, koefisien korelasi, koefisien determinasi dan uji t sehingga hasil penelitian menunjukkan bahwa lingkungan kerja berpengaruh positif dan signifikan terhadap kinerja pegawai. pada Dinas Perumahan, Permukiman dan Kantor Pertanahan Provinsi Sulawesi Selatan
\end{abstract}

Kata Kunci: lingkungan kerja, kepuasan kerja

Abstract: The Effect of Work Environment on Job Satisfaction Employees at the Office of the Housing, Settlement and Land Office of South Sulawesi Province. This study aims to determine the effect of work environment on job satisfaction employees at the housing, residential and land office of South Sulawesi province. The types of data used in this research are qualitative and quantitative data. The data sources are obtained from primary and secondary data by distributing questions or statements to respondents. The number of respondents used is 54 people. The method used in processing the data is simple linear regression analysis, correlation coefficient, coefficient of determination and test so that the research results show that the work environment has a positive and significant effect on employee performance.at the Office of the Housing, Settlement and Land Office of South Sulawesi Province

Keywords: work environment, job satisfaction 


\section{A. PENDAHULUAN}

\section{Latar Belakang}

Sumber daya manusia adalah salah satu faktor yang sangat penting yang tidak dapat dilepaskan dari organisasi, baik diinstansi ataupun perusahaan bahkan sumber daya manusia juga merupakan kunci yang menentukan perkembangan suatu organisasi. Pada hakikatnya sebuah organisasi itu digerakkan oleh sumber daya manusia sebagai pemikir dan perencana untuk mencapai tujuan organisasi.

Sumber daya manusia (SDM) yang biasa dalam sebuah instansi disebut dengan pegawai merupakan tenaga kerja yang sudah terdaftar dan telah mengikuti mekanisme kerja standar hak dan kewajiban dalam mencapai tujuan instansi sehingga menjadi cepat dan efektif.

Hal ini menjadi perhatian khusus dalam organisasi, bagaimana pencapaian tujuan organisasi yang efektif melalui kinerja yang baik. Manejemen sumber daya manusia pada dasarnya adalah proses yang terdiri atas perencanaan, pengorganisasian dan pengendalianpengendalian dari kegiatan yang berhubungan dengan analisis sebuah pekerjaan, pengadaan dan pengembangan sebuah pekerjaan, serta sifatnya sebuah evaluasi pekerjaan.

Lingkungan kerja menjadi salah satu faktor dari kepuasan kerja. Secara umum, lingkungan kerja adalah kehidupan fisik, sosial, dan psikologi dalam instansi yang memengaruhi kinerja ataupun kepuasan kerja serta produktivitas pegawai.
Lingkungan kerja juga menjadi faktor yang bisa meningkatkan kepuasan kerja karyawan atau bahkan menurunkan. Ketika pegawai bekerja di lingkungan kerja yang baik, maka ide, produktivitas, dan kepuasan kerja pegawai. bisa meningkat. Sebaliknya, jika lingkungan kerja tidak baik maka akan mempengaruhi tingkat kepuasan pegawai sehingga bisa berdampak terjahadap output kinerja yang dihasilkan.

Hal inilah yang mendasari sehingga peneliti tertarik untuk melakukan penelitian berkaitan dengan pengaruh lingkungan kerja terhadap kepuasan kerja pegawai pada Kantor Dinas Perumahan, Kawasan Permukiman dan Pertanahan Provinsi Sulawesi Selatan?

\section{Rumusan Masalah}

Berdasarkan dari latar belakang yang disampaikan maka yang menjadi masalah dalam penelitian ini adalah “Apakah Lingkungan Kerja berpengaruh terhadap Kepuasan Kerja Pegawai pada Kantor Dinas Perumahan, Kawasan Permukiman dan Pertanahan Provinsi Sulawesi Selatan?

\section{Tujuan Penelitian}

Adapun tujuan yang ingin dicapai dari penelitian ini adalah untuk mengetahui pengaruh lingkungan kerja terhadap kepuasan kerja pegawai pada Kantor Dinas Perumahan, Kawasan Permukiman dan Pertanahan Provinsi Sulawesi Selatan.

B. TINJAUAN LITERATUR

1. Pengertian Manajemen Sumber Daya Manusia

Menurut Handoko

$(2017: 4)$ 
"Manajemen sumber daya manusia adalah penarikan, seleksi, pengembangan, pemeliharaan, dan penggunaan sumber daya manusia untuk mencapai baik tujuantujuan individu maupun organisasi". Menurut Edison, dkk (2017:10): "manajemen sumber daya manusia adalah manajemen yang memfokuskan diri memaksimalkan kemampuan karyawan atau anggotanya melalui berbagai langkah strategis dalam rangka meningkatkan kinerja pegawai/karyawan menuju pengoptimalan tujuan organisasi".Sedangkan menurut Hasibuan (2016:10) 'Manajemen sumber daya manusia adalah ilmu dan seni mengatur hubungan antara yang satu dengan yang lain dan peranan tenaga kerja efektif dan efisien tentunya akan sangat membantu terwujudnya suatu tujuan perusahaan yang dia inginkan dalam mencapai yang diinginkan, karyawan, dan masyarakat dalam mencapai hal yang dia inginkan demi memajukan suatu perusahaan tersebut itu".

Dari beberapa pengertian manajemen sumber daya manusia yang telah dijabarkan oleh para ahli, maka peneliti dapat menyimpulkan bahwa manajemen sumber daya manusia dapat diartikan bahwa bagaimana cara mengatur, menggunakan dan mengembangkan sumber daya manusia yang ada dengan cara menerapkan fungsi-fungsi manajemen agar tujuan dalam suatu organisasi tercapai.

\section{Pengertian Lingkungan Kerja}

Menurut Sedarmayanti (2017:1) "lingkungan kerja adalah keseluruhan alat perkakas dan bahan yang dihadapi lingkungan sekitarnya dimana seorang bekerja, metode kerjanya serta pengaturan kerjanya baik sebagai perseorangan maupun sebagai kelompok". Sedangkan menurut Mardiana dalam Sudaryo, dkk (2018:47) "menyatakan bahwa lingkungan kerja adalah lingkungan dimana pegawai melakukan pekerjaannya sehari-hari”.

Adapun menurut Nitisemito (2000:183) berpendapat bahwa "lingkungan kerja adalah tempat dimana karyawan melakukan aktivitas setiap harinya. Lingkungan kerja dikatakan baik atau sesuai apabila manusia dapat melaksanakan kegiatan secara optimal, sehat, aman dan nyaman".

Berdasarkan definisi dijelaskan oleh para ahli diatas, maka penulid dapat disimpulkan bahwa lingkungan kerja merupakan suatu kondisi dimana para karyawan bekerja, baik menyangkut aspek fisik, maupun yang menyangkut aspek sosial dalam suatu organisasi atau perusahaan yang dapat mempengaruhi karyawan dalam menjalankan tugas dan pekerjaannya setiap hari.

\section{Indikator-indikator Lingkungan Kerja}

Menurut Sudaryo, Aribowo, Sofiati (2018:51-59) indicator - indikator lingkungan kerja adalah sebagai berikut:

a. Penerangan

Penerangan merupakan faktor yang sangat penting dalam suatu kantor karena dapat memperlancar pekerjaan dikantor. Apalagi seorang karyawan yang pekerjaannya berkaitan dengan ketatabukuan maka tulisan harus terlihat jelas tanpa terlindungi oleh bayangan. 
b. Pewarnaan

Banyak instansi pemerintah yang sampai saat ini kurang memperhatikan masalah warna, padahal pengaruhnya cukup besar terhadap para pegawai dalam melaksanakan tugas-tugasnya, karena warna dapat memengaruhi manusia.

c. Kebersihan

Untuk menjaga kesehatan para pegawai, maka semua ruangan yang ada dalam suatu kantor harus dijaga kebersihannya. Lingkungan kerja yang bersih akan menimbulkan perasaan yang tenang dalam bekerja, sehingga pegawai dapat bekerja dengan sebaik-baiknya.

d. Penukaran udara

Manusia sebagai makhluk hidup lainnya memerlukan udara yang segar dan nyaman. Udara yang segar dan nyaman memiliki kompisisi kimia yang baik, dengan suhu dan kelembaban yang tidak menganggu pernapasan dan kesegaran badan.

e. Suara/ kebisingan

Dengan mengetahui akibat yang ditimbulkan oleh suara bising tersebut, hendaknya pihak kantor dapat mengurangi kebisingan seminimal mungkin. Tujuan dari pengaturan dan pengendalian suara bising dalam ruangan kerja adalah untuk menjaga kepekaan pendengaran dari pegawai.

f. Keamanan

Hal yang termasuk dalam keamanan adalah keamanan atas barang-barang yang menjadi milik pegawai pada saat pegawai tersebut berada dalam lingkungan kantor. Misalnya sebagian besar dari pegawai kantor datang dengan kendaraan sendiri yaitu sepeda, sepeda motor, maupun mobil.

\section{Pengertian Kepuasan Kerja}

Menurut Robbins (2015: 170) bahwa "kepuasan kerja adalah suatu sikap umum terhadap pekerjaan seseorang sebagai perbedaan antara banyaknya ganjaran yang diterima pekerja dengan banyaknya ganjaran yang diyakini seharusnya diterima. Kepuasan kerja merupakan hal penting yang dimiliki individu di dalam bekerja. Setiap individu pekerja memiliki karakteristik yang berbeda-beda, maka tingkat kepuasan kerjanya pun berbeda-beda pula tinggi rendahya kepuasan kerja tersebut dapat memberikan dampak yang tidak sama". Selanjutnya Sutrisno (2017:74) "Kepuasan kerja adalah suatu sikap karyawan terhadap pekerjaan yang berhubungan denga situasi kerja, kerja sama antar karyawan, imbalan yang diterima dalam kerja, dan hal-hal yang menyangkut faktor fisik dan psikologis.

Dari beberapa pengertian diatas maka penulis dapat menyimpulkan bahwa kepuasan kerja adalah suatu bentuk sikap sesorang dalam pekerjaannya mengenai hasil yang telah dilakukan apakah sesuai ataupun tidak sesuai terhadap keinginan yang iya harapkan. Kepuasan kerja meliputi perasaan seseorang terhadap hasil kerja yang telah diberikan apakah maksimal ataupun tidak maksimal. 
Semakin banyak aspek-aspek dalam pekerjaan yang sesuai dengan keinginan individu tersebut, maka semakin tinggi tingkat kepuasan yang dirasakannya, sebaliknya semakin sedikit aspek-aspek dalam pekerjaan yang sesuai dengan keinginan individu, maka semakin rendah tingkat kepuasan yang dirasakannya.

\section{Indikator-indikator Kepuasan kerja \\ Menurut Sudaryo

kepuasan kerja dipengaruhi oleh beberapa indikator, antara lain:

a. Kemangkiran

Pegawai yang tinggi tingkat kepuasan kerjanya akan rendah tingkat kemangkirannya. Sebaliknya pegawai yang rendah tingkat kepuasan kerjanya akan cenderung tinggi tingkat kemangkirannya.

b. Keinginan pindah

Tidak dapat disangkal bahwa salah satu faktor penyebab timbulnya keinginan pindah kerja adalah ketidakpuasan di tempat bekerja sekarang.

Sebab-sebab ketidakpuasan itu beranekaragam, seperti pengahasilan rendah atau dirasakan kurang memadai, kondisi kerja yang kurang memuaskan, hubungan yang tidak serasi baik dari atasan maupun dari rekan sekerja, pekerjaan yang tidak sesuai, dan berbagai faktor lainnya.

c. Kinerja karyawan

Pengertian kinerja adalah hasil kerja secara kualitas dan kuantitas yang dicapai oleh seseorang karyawan dalam kemampuan melaksanakan tugas-tugas sesuai dengan tanggung jawab yang diberikan oleh atasan kepadanya.

d. Rekan kerja

Rekan kerja yang bersahabat, kerja sama rekan sekerja atau kelompok kerja adalah sumber kepuasan kerja bagi pekerja secara individual, sementara itu kelompok kerja dapat memberikan dukungan, nasihat, atau saran kepada sesama rekan kerja. Rekan kerja yaitu temateman kepada siapa seorang berinteraksi.

e. Kenyaman kerja karyawan

Pada umumnya karyawan cenderung lebih senang dengan adanya kondisi lingkungan kantor tempat kerja yang bain dan nyaman, sehingga efisiensi kerja suatu organisasi dapat tercapai dengan baik.

\section{Teori Hubungan Lingkungan Kerja terhadap Kepuasan Kerja}

Lingkungan kerja yang baik secara fisik maupun non fisik sangat diharapkan oleh karyawan untuk bekerja secara maksimal, begitu pula sebaliknya jika lingkungan sekitar buruk, maka karyawan tidak akan mempunyai kepuasan dalam bekerja (Anas, 2013). "Lingkungan kerja yang meliputi hubungan kerja yang harmonis, target yang jelas, iklim kerja yang dinamis, fasilitas kerja yang memadai juga dapat mempengaruhi kepuasan kerja karyawan" Mangkunegara dalam Dhermawan, (2012). Oleh karena itu lingkungan kerja memiliki pengaruh terhadap kepuasan kerja karyawan 


\section{Kerangka Pikir}

\section{Gambar 1: Kerangka Pikir}

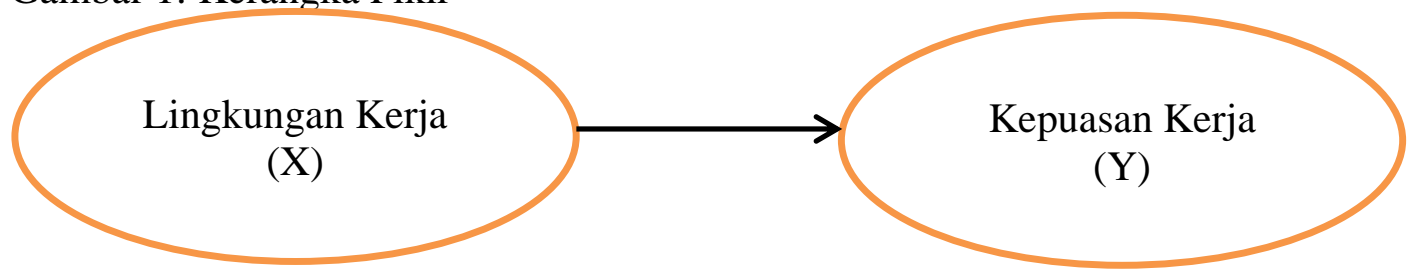

Sumber: Data diolah, 2020

\section{Hipotesis}

Berdasarkan dari rumusan masalah maka hipotesis pada penelitian ini adalah diduga bahwa lingkungan kerja berpengaruh positif signifikan terhadap kepuasan kerja pegawai pada Kantor Dinas Perumahan, Kawasan Permukiman Dan Pertanahan Provinsi Sulawesi Selatan.

\section{METODE PENELITIAN}

1. Pengumpulan Data

Metode yang digunakan dalam pengumpulan adalah sebagai berikut:

a. Observasi, yaitu peneliti mengamati yang dikerjakan orang, mendengarkan yang mereka ucapkan, dan berpartisipasi dalam aktivitas orang lain untuk memperoleh informasi yang diinginkan.

b. Angket (Quesionery), yaitu Pengumpulan data yang dilakukan melalui daftar pertanyaan / pernyataan yang disiapkan untuk responden.

2. Jenis dan Sumber Data

a. Jenis data yang digunakan dalam penelitian ini, yaitu:

1) Data kualitatif

Data ini diperoleh dalam bentuk informasi secara lisan maupun tertulis. Seperti wawancara, dan penyebaran kuesioner kepada responden.

2) Data kuantitatif

Data kuantitatif merupakan data yang diperoleh dalam bentuk angka-angka, melalui dokumen yang ada dalam perusahaan serta berbagai literature.

3. Sumber data yang digunakan dalam penelitian ini, yaitu:

a. Data primer adalah data yang diperoleh secara langsung dari sumber aslinya. Data primer ini diperoleh melalui hasil pengamatan dan melalui koesioner yang dibagikan.

b. Data Sekunder adalah data yang dikumpulkan secara tidak langsung dari sumbernya. Data sekunder ini diperoleh melalui dokumen yang ada dalam kantor serta berbagai literature bahan kuliah yang berkaitan dengan penelitian ini.

4. Populasi dan Sampel

a. Populasi

Menurut Sugiyono (2017:117) "Populasi adalah wilayah generalisasi yang terdiri atas: obyek dan subyek yang 
mempunyai kualitas dan karakteristik tertentu yang ditetapkan oleh peneliti untuk dipelajari dan kemudian ditarik kesimpulannya". Populasi dalam penelitian ini adalah seluruh pegawai pada Kantor Dinas Perumahan, Kawasan Permukiman dan Pertanahan Provinsi Sulawesi Selatan. yang berjumlah 116 orang.

\section{b. Sampel}

Menurut Sugiyono (2017:118) "Sa mpel merupakan bagian dari jumlah dan karakteristik yang dimiliki oleh populasi tersebut". Jumlah sampel yang diambil pada Kantor Dinas Perumahan, Kawasan Permukiman dan Pertanahan Provinsi Sulawesi Selatan. adalah 54 orang. Jumlah sampel tersebut menggunakan formulasi slovin :

$$
\boldsymbol{n}=\frac{\mathrm{N}}{1+\mathrm{N}(e)^{2}}
$$

Di mana, $\mathrm{N}=$ jumlah populasi; $\mathrm{n}=$ jumlah sampel dan $\mathrm{e}=\operatorname{error}(10 \%)$

$$
\begin{gathered}
\boldsymbol{n}=\frac{116}{1+116(10 \%)^{2}}=\frac{116}{2,16} \\
=53,70=54
\end{gathered}
$$

5. Metode Analisis Data

a. Analisis regresi linear sederhana

b. Koefisien korelasi $n$

$$
\begin{aligned}
& b=\frac{n\left(\sum X Y\right)-\left(\sum X\right)\left(\sum Y\right)}{n\left(\sum X^{2}\right)-\left(\sum X\right)^{2}} \\
& a=\frac{\sum Y-(b)\left(\sum X\right)}{n}
\end{aligned}
$$

Untuk dapat menghitung koefisien korelasi pearsonnya digunakan formulasi sebagai berikut :

$$
r=\frac{n\left(\sum X Y\right)-\left(\sum X\right)\left(\sum Y\right)}{\sqrt{\left\{n\left(\sum X^{2}\right)-\left(\sum X\right)^{2}\right\}\left\{n\left(\sum Y^{2}\right)-\left(\sum Y\right)^{2}\right\}}}
$$

Analisis regresi linear sederhana yaitu metode perhitungan untuk mengetahui pengaruh antara variabel independen (X) yang dalam penelitian ini adalah lingkungan kerja dan variabel dependen (Y) dalam penelitian ini adalah kepuasan kerja dari analisis regresi linear sederhana. Adapun rumus regresi linear sederhana menurut Sugiyono (2017:261) adalah sebagai berikut:

$$
Y=a+b X
$$

Dimana:

$X=$ Variabel independen (Lingkungan Kerja)

$Y=$ Variabel dependen (Kepuasan kerja)

$a=$ Konstanta

$b=$ Koefisien regresi yang berhubungan dengan variabel X

(Lingkungan Kerja) terhadap variabel $\mathrm{Y}$ (Kepuasan kerja)

Untuk menghitung nilai konstanta maka akan digunakan rumus sebagai berikut nilai:

Koefisien korelasi (r) bertujuan untuk mengetahui hubungan linear dan arah hubungan dua variabel acak. Jika koefisien korelasi positif, maka kedua variabel mempunyai hubungan searah. Artinya jika nilai 
variabel $\mathrm{X}$ tinggi, maka nilai variabel $\mathrm{Y}$ akan tinggi pula. Sebaliknya, jika koefisien korelasi negatif, maka kedua variabel mempunyai hubungan terbalik. Artinya jika nilai variabel $\mathrm{X}$ tinggi, maka nilai variabel $\mathrm{Y}$ akan menjadi rendah dan sebaliknya.

$\mathrm{r} \quad=$ Koefisien korelasi

$\mathrm{n} \quad=$ Jumlah sampel penelitian
$\mathrm{X}$ dan $\mathrm{Y}=$ Nilai dalam variabel $\mathrm{X}$ dan $\mathrm{Y}$

$\mathrm{X}^{2}$ dan $\mathrm{Y}^{2}=$ Nilai perkalian dalam variabel $X$ dan $Y$

$\mathrm{XY} \quad=$ Perkalian dari skor dalam variabel $\mathrm{X}$ dan $\mathrm{Y}$

Berikut tabel pedoman interpretasi kriteria koefisien korelasi (r):

Tabel 1 : Pedoman interpretasi kriteria koefisien korelasi (r)

\begin{tabular}{|c|c|c|}
\hline NO & Interval $(\%)$ & Kriteria \\
\hline 1 & $0,00-0,199$ & Sangat rendah \\
\hline 2 & $0,20-0,399$ & Rendah \\
\hline 3 & $0,40-0,599$ & Sedang \\
\hline 4 & $0,60-0,799$ & Kuat \\
\hline 5 & $0,80-1,000$ & Sangat Kuat \\
\hline
\end{tabular}

Sumber: Sugiyono (2017:184)

a. Koefisien determinasi $\left(\mathrm{r}^{2}\right)$

Setelah diketahui korelasinya, kemudian koefisien determinasi digunakan untuk mengetahui seberapa kuat pengaruh kedua variabel dengan formulasi sebagai berikut : korelasi

$$
\begin{aligned}
& d=r^{2} \times 100 \% \\
& r^{2}=\text { Kuadrat koefisien }
\end{aligned}
$$

b. Uji t

Uji $\mathrm{t}$ adalah sesuatu yang dapat diukur dengan kasat mata Uji Kemudian untuk menguji hipotesis bahwa terdapat pengaruh positif dan signifikan antara lingkungan kerja terhadap kepuasan kerja pegawai pada Kantor Dinas
Perumahan, Kawasan Permukiman dan Pertanahan Provinsi Sulawesi Selatan, dilakukan perbandingan antara t-hitung dengan t-tabel dengan taraf nyata $0,1(10 \%)$. Jadi untuk koefisien korelasi (r), diuji dengan menggunakan uji statistik sebagai berikut:

$\mathrm{t}=\frac{r \sqrt{n-2}}{\sqrt{t-(r)^{2}}}$

Keterangan:

$\mathrm{t}=$ Distribusi nilai

$r=$ Koefisien korelasi

Berikut ini adalah uji dan kriteria hipotesis sebagai berikut:

1) Uji hipotesis

a) $\mathrm{H}_{\mathrm{o}}: \mathrm{r} \leq 0$ (lingkungan kerja 
tidak berpengaruh terhadap kepuasan kerja pegawai).

b) $\mathrm{H}_{\mathrm{o}}: \mathrm{r}>0$ (lingkungan kerja berpengaruh terhadap kepuasan kerja).

2) Kriteria Hipotesis sebagai

\section{HASIL DAN PEMBAHASAN}

Berikut adalah data yang digunakan untuk menentukan berikut:

a) Apabila t. tabel $\leq$ t. hitung $\leq$ t. tabel maka $\mathrm{H} 0$ di terima.

b) Apabila t. hitung < -t. tabel atau t.hitung $>$ t. tabel maka H0 ditolak persamaan regresi linear sederhana sebegai berikut:

Tabel 2: Hasil pengolahan tabulasi

\begin{tabular}{|c|c|c|c|c|c|}
\hline \multirow{2}{*}{ Responden } & \multicolumn{2}{|c|}{ Lingkungan Kerja } & \multicolumn{2}{|c|}{ Kepuasan } & \multirow{2}{*}{$X Y$} \\
\hline & $\mathrm{X}$ & $\mathrm{X} 2$ & $\mathrm{Y}$ & $\mathrm{Y} 2$ & \\
\hline 1 & 46 & 2116 & 43 & 1849 & 1978 \\
\hline 2 & 45 & 2025 & 45 & 2025 & 2025 \\
\hline 3 & 45 & 2025 & 46 & 2116 & 2070 \\
\hline 4 & 46 & 2116 & 43 & 1849 & 1978 \\
\hline 5 & 46 & 2116 & 44 & 1936 & 2024 \\
\hline 6 & 42 & 1764 & 42 & 1764 & 1764 \\
\hline 7 & 48 & 2304 & 45 & 2025 & 2160 \\
\hline 8 & 44 & 1936 & 43 & 1849 & 1892 \\
\hline 9 & 47 & 2209 & 45 & 2025 & 2115 \\
\hline 10 & 44 & 1936 & 43 & 1849 & 1892 \\
\hline 11 & 44 & 1936 & 43 & 1849 & 1892 \\
\hline 12 & 45 & 2025 & 42 & 1764 & 1890 \\
\hline 13 & 47 & 2209 & 43 & 1849 & 2021 \\
\hline 14 & 46 & 2116 & 47 & 2209 & 2162 \\
\hline 15 & 45 & 2025 & 42 & 1764 & 1890 \\
\hline 16 & 40 & 1600 & 48 & 2304 & 1920 \\
\hline 17 & 45 & 2025 & 42 & 1764 & 1890 \\
\hline 18 & 43 & 1849 & 44 & 1936 & 1892 \\
\hline 19 & 44 & 1936 & 44 & 1936 & 1936 \\
\hline 20 & 45 & 2025 & 42 & 1764 & 1890 \\
\hline 21 & 46 & 2116 & 44 & 1936 & 2024 \\
\hline 22 & 47 & 2209 & 44 & 1936 & 2068 \\
\hline 23 & 45 & 2025 & 45 & 2025 & 2025 \\
\hline 24 & 46 & 2116 & 44 & 1936 & 2024 \\
\hline 25 & 46 & 2116 & 45 & 2025 & 2070 \\
\hline
\end{tabular}




\begin{tabular}{|c|c|c|c|c|c|}
\hline 26 & 45 & 2025 & 42 & 1764 & 1890 \\
\hline 27 & 47 & 2209 & 43 & 1849 & 2021 \\
\hline 28 & 44 & 1936 & 41 & 1681 & 1804 \\
\hline 29 & 46 & 2116 & 40 & 1600 & 1840 \\
\hline 30 & 44 & 1936 & 46 & 2116 & 2024 \\
\hline 31 & 50 & 2500 & 48 & 2304 & 2400 \\
\hline 32 & 43 & 1849 & 41 & 1681 & 1763 \\
\hline 33 & 45 & 2025 & 46 & 2116 & 2070 \\
\hline 34 & 41 & 1681 & 45 & 2025 & 1845 \\
\hline 35 & 43 & 1849 & 44 & 1936 & 1892 \\
\hline 36 & 48 & 2304 & 45 & 2025 & 2160 \\
\hline 37 & 45 & 2025 & 42 & 1764 & 1890 \\
\hline 38 & 44 & 1936 & 46 & 2116 & 2024 \\
\hline 39 & 41 & 1681 & 39 & 1521 & 1599 \\
\hline 40 & 46 & 2116 & 44 & 1936 & 2024 \\
\hline 41 & 46 & 2116 & 44 & 1936 & 2024 \\
\hline 42 & 46 & 2116 & 46 & 2116 & 2116 \\
\hline 43 & 43 & 1849 & 43 & 1849 & 1849 \\
\hline 44 & 46 & 2116 & 46 & 2116 & 2116 \\
\hline 45 & 43 & 1849 & 42 & 1764 & 1806 \\
\hline 46 & 46 & 2116 & 45 & 2025 & 2070 \\
\hline 47 & 43 & 1849 & 45 & 2025 & 1935 \\
\hline 48 & 43 & 1849 & 41 & 1681 & 1763 \\
\hline 49 & 44 & 1936 & 44 & 1936 & 1936 \\
\hline 50 & 46 & 2116 & 45 & 2025 & 2070 \\
\hline 51 & 43 & 1849 & 46 & 2116 & 1978 \\
\hline 52 & 46 & 2116 & 44 & 1936 & 2024 \\
\hline 53 & 46 & 2116 & 45 & 2025 & 2070 \\
\hline 54 & 43 & 1849 & 44 & 1936 & 1892 \\
\hline Total & 2423 & 108905 & 2370 & 104204 & 106387 \\
\hline
\end{tabular}

Sumber: Data diolah 2021

Untuk memperoleh nila $a$ dan $b$, maka hasil perhitungan diatas didistribusikan kedalam persamaan $a$ dan $b$ Untuk nilai $b$ :

$$
\mathrm{b}=\frac{\mathrm{n}\left(\sum \mathrm{xy}\right)-\left(\sum \mathrm{x}\right)\left(\sum \mathrm{y}\right)}{\mathrm{n}\left(\sum \mathrm{x}^{2}\right)-\left(\sum \mathrm{x}\right)^{2}}
$$

$\mathrm{b}=\frac{54(106387)-(2423)(2370)}{54(108905)-(2423)^{2}}$

$\mathrm{b}=\frac{5.744 .898-5.742 .510}{5.880 .870-5.870 .929}$

$\mathrm{b}=\frac{2.388}{9.341}$

$\mathrm{b}=0,25$

Sedangkan nilai a dihitung dengan cara: 


$$
\begin{aligned}
& a=\frac{\sum y-b \sum x}{n} \\
& a=\frac{2370-0,25(2423)}{54} \\
& a=\frac{2370-605,75}{54} \\
& a=32,67
\end{aligned}
$$

Dari perhitungan tersebut, maka persamaan regresi linear sederhana antara variabel $\mathrm{X}$ dan $\mathrm{Y}$ adalah:

$$
\begin{aligned}
& Y=a+b X \\
& Y=32,67+0,25 X
\end{aligned}
$$

Dari hasil perhitungan diatas, maka diketahui bahwa nilai $b$ (koefisien regresi) sebesar 0,25yang berarti bahwa setiap perubahan nilai variabel independen $X$ (lingkungan kerja) sebesar 1 poin, maka akan diimbangi dengan perubahan nilai variabel Y (kepuasan) sebesar 0,25. Nilai a

$$
\begin{array}{cc}
\mathrm{r} & = \\
\frac{\mathrm{n}\left(\sum \mathrm{xy}\right)-\left(\sum \mathrm{x}\right)\left(\sum \mathrm{y}\right)}{\sqrt{\left[\mathrm{n}\left(\sum \mathrm{x}^{2}\right)-\left(\sum \mathrm{x}\right)^{2}\right] \cdot\left[\mathrm{n}\left(\sum \mathrm{y}^{2}\right)-\left(\sum \mathrm{y}\right)^{2}\right]}} & \\
\mathrm{r} & = \\
\frac{54(106387)-(2423)(2370)}{\sqrt{\left[54(108905)-(2423)^{2}\right] \cdot\left[54(104204)-(2370)^{2}\right]}} \\
\mathrm{r} \quad=
\end{array}
$$

(konstanta) sebesar 32,67 artinya bahwa tanpa adanya variabel $\mathrm{X}$ (lingkungan kerja) nilai $\mathrm{Y}$ (kepuasan) tetap senilai 32,67 .

1. Analisis koefisien korelasi

Untuk mengetahui keeratan hubungan antara perilaku lingkungan kerja terhadap kepuasan kerja pegawai pada Kantor Dinas Perumahan, Kawasan Permukiman dan Pertanahan Provinsi Sulawesi Selatan maka penulis menggunakan persamaan koefisien korelasi dengan rumus seperti berikut:

Dimana:

$$
\begin{aligned}
& \mathrm{r}=\text { koefsien korelasi } \\
& \mathrm{n}=\text { sampel penelitian } \\
& \mathrm{X}=\text { lingkungan kerja } \\
& \mathrm{Y}=\text { kepuasan kerja }
\end{aligned}
$$

$$
\begin{gathered}
\frac{5.744 .898-5.742 .510}{\sqrt{(5.880 .870-5.870 .929)(5.627 .106-5.616 .900)}} \\
r=\frac{2.388}{\sqrt{(9.941)(10.206)}} \\
r=\frac{2.388}{\sqrt{(101.457 .846)}} \\
r=0,23
\end{gathered}
$$

$$
r^{2}=0,5290 \text { atau } 52,90 \%
$$

Hal ini berarti bahwa pengaruh korelasi (r) diatas, dapat diketahui nilai koefisien korelasi $r=0,23$, ini menunjukkan bahwa lingkungan kerja dengan kepuasan pegawai pada Kantor Dinas Perumahan, Kawasan Permukiman dan Pertahanan Provinsi Sulawesi Selatan saling berpengaruh positif.

2. Analisis Koefisien Determinasi

Untuk mengetahui seberapa besar pengaruh variabel $\mathrm{x}$ dan variabel $\mathrm{y}$, maka penulis menggunakan koefisien determinasi $\mathrm{r}^{2}$ sebagai berikut:

$$
\begin{aligned}
& r^{2}=r \times r \\
& r^{2}=0,23 \times 0,23
\end{aligned}
$$

lingkungan kerja terhadap kepuasan pegawai pada Kantor Dinas Perumahan, Kawasan Permukiman dan Pertahanan Provinsi Sulawesi Selatan sebesar 52,90\% sedangkan sisanya $47,10 \%$ dipengaruhi variabel lain diluar penelitian.

3. Uji Hipotesis dengan Uji Parsial (uji t)

Untuk membuktikan hipotesis diatas, maka digunakan uji hipotesis yang disebut uji t. Uji t ini digunakan untuk menguji ada atau tidaknya hubungan antara lingkungan kerja terhadap kepuasan pegawai pada Kantor Dinas Perumahan, 
Kawasan Permukiman dan Pertanahan Provinsi Sulawesi Selatan.

Adapun langkah-langkah dalam penguji hipotesis adalah sebagai berikut:

a. Uji Hipotesis satu arah:

$\mathrm{H}_{\mathrm{o}}: \mathrm{r} \leq 0$ (lingkungan kerja tidak berpengaruh terhadap kepuasan kerja pegawai).

$\mathrm{H}_{\mathrm{o}}$ : $\mathrm{r}>0$ (lingkungan kerja berpengaruh terhadap kepuasan kerja pegawai).

b. Perhitungan uji t

$$
\mathrm{t}=\mathrm{r} \frac{\sqrt{n-2}}{\sqrt{1-r^{2}}}
$$

Keterangan :

$r$ : koefisien regresi

$\mathrm{n}$ : jumlah responden

nilai $t$ dapat dihitung sebagai berikut:

$$
\begin{aligned}
& t=\frac{0.23 \sqrt{54-2}}{\sqrt{1-0.23^{2}}} \\
& t=\frac{0,23 \sqrt{52}}{\sqrt{1-0,5290}} \\
& t=\frac{1.658}{0,471} \\
& t=3.520
\end{aligned}
$$

Berdasarkan hail perhitungan statistik uji-t, maka diperoleh nilai thitung sebesar 3.520 maka selanjutnya perlu dibandingkan dengan nilai $\mathrm{t}$ - tabel untuk mendapatkan derajat bebas $(\mathrm{db})$ atau degress of freedom (df) dengan rumus sebagai berikut:

$$
\mathrm{df}=\mathrm{n}-\mathrm{k}
$$

Dimana:

$$
\begin{aligned}
& \mathrm{n}=\text { Jumlah Responden } \\
& \mathrm{k}=\text { Jumlah Variabel } \\
& \mathrm{df}=54-2 \\
& \mathrm{df}=52
\end{aligned}
$$

Setelah nilai df telah diketahui, maka nilai t-tabel yang digunakan adalah
1,298 dengan nilai $\alpha=0,1$ (10\%). Dari hasil pengujian signifikasi korelasi (uji-t) dapat dilihat bahwa t-hitung $>\mathrm{t}$-tabel dimana t-hitung $=3.520>$ t-tabel $=1,298$. Hasil uji-t ini menunjukkan bahwa menolak $\mathrm{H0}$ dan menerima Ha.

Dari hasil penelitian ini menunjukkan bahwa lingkungan kerja berpengaruh positif dan sgnifikan terhadap kepuasan kerja pegawai pada Kantor Dinas Perumahan, Kawasan Permukiman dan Pertanahan Provinsi Sulawesi Selatan. Sehingga dapat diambil kesimpulan bahwa hipotesis yang diajukan yaitu dapat diterima.

Penelitian ini diperkuat oleh
pendapat ahli yang menyatakan
"Lingkungan kerja yang meliputi hubungan kerja yang harmonis, target yang jelas, iklim kerja yang dinamis, fasilitas kerja yang memadai juga dapat mempengaruhi kepuasan kerja karyawan" Mangkunegara dalam Dhermawan, (2012). Disamping itu penelitian ini juga sejalan dengan penelitian yang dilakukan oleh Quinerita Stevani Aruan (2015) yang berjudul Pengaruh Lingkungan Kerja terhadap Kepuasan Kerja Pegawai Kantor Dinas Perhubungan Kabupaten Pasangkayu Mamuju Utara dimana hasil penelitiaannya menujukkan bahwa lingkungan kerja berpengaruh positif dan signifikan terhadap kepuasan kerja pegawai pada Kantor Dinas Perhubungan Kabupaten Pasangkayu Mamuju Utara. Dimana nilai regresi linear sederhananya adalah $\mathrm{Y}=1,172+0,290 \mathrm{X}$ sedangkan nilai t-hitung $(4,587)$ lebih besar dari nilai ttabel $(2,004)$ 


\section{DAFTAR PUSTAKA}

Aruan, Quenarita Stevani. 2015. Pengaruh lingkungan kerja terhadap kepuasan kerja karyawan lapangan epartement Grasberg Power Distribution PT. Freeport Indonesia. Jurnal Bisnis dan Manajemen, Vol.27 (2) : 141-162.

Edison Emron, Anwar Yohny, Komariyah Imas, 2017. Manajemen Sumber Daya Manusia Strategi Dan Perubahan Dalam Rangka Meningkatkan Kinerja Pegawai Dan Organisasi. Edisi kedua: Alfabeta. Bandung.

Hasibuan, Malayu S.P, 2016. Organisasi \& Motivasi, Dasar Peningkatan Produktivitas: PT Bumi Aksara. Jakarta.

2010. Manajemen Sumber Daya Manusia. Bandung : Alfabeta

Handoko Hani, 2017. Manajemen Personalia dan Sumber Daya Manusia. Edisi kedua: BPFEYogyakarta. Yogyakarta.

Hamali Arif Yusuf, 2018. Pemahaman Manajemen Sumber Daya Manusia. Edisi ketiga: PT. Buku Seru. Bandung.

(2016). Manajemen Sumber Daya Manusia Teori dan Aplikasi. Edisi ketiga: Alfabeta. Bandung.

Kasmir Dr, 2017. Manajemen Sumber Daya Manusia (Teori dan Praktik). Edisi ketiga: Raja Gravindo Persada. Depok.
Nitisemito, Sugianti. 2012. Manajemen Sumber Daya Manusia. Yogyakarta : Andi.

2016. Manajemen Sumber Daya Manusia (Teori dan Praktik). Edisi kedua: Raja Gravindo Persada. Depok.

Rahmat, 2017. Manajemen Sumber Daya Manusia. Cetakan pertama: Penerbit PT Umitoho Ukhuwah Grafika. Makassar.

Sedarmayanti, 2017. Manajemen Sumber Daya Manusia Reformasi Birokrasi dan Manajemen Pegawai Negeri Sipil Edisi Revisi: PT. Refika Aditama. Bandung.

Sustrisno, Edy. 2019. Manajemen Sumber Daya Manusia. Predanamedia Group (kencana), Jakarta

Siswanti, Yuni, 2018. Pengaruh Kepemimpinan terhadap Kinerja Karyawan: Studi Kasuk Bank. Jurnal Ekonomi dan Bisnis, Vol.4, No. 1: 110-117. Lampung.

Sugiyono, 2017. Metode Penelitian Kuantitatif, Kualitatif dan $R \& D$. Edisi kedua: Alfabeta. Bandung.

Sudaryo, Yoyo, dkk, 2018. Manajemen Sumber Daya Manusia. Kompensasi Tidak Langsung dan Lingkungan Kerja Fisik. Edisi Pertama: CV. Andi Offset. Yogyakarta.

Mangkunegara. 2011. Manajemen Sumber Daya Manusia. Yogyakarta : Alfabeta.

Moh. As'ad, Wibowo. 2005. Pengaruh Lingkungan Kerja Terhadap Kepuasan Kerja Karyawan. Universitas widyatama. 